Check for updates

Cite this: RSC Adv., 2018, 8, 39047

Received 27th September 2018 Accepted 16th November 2018

DOI: $10.1039 / \mathrm{c} 8 \mathrm{ra0} 0022 \mathrm{~d}$

rsc.li/rsc-advances

\section{Modification of dry/wet hybrid fabrication method for preparing a perovskite absorption layer on a PCBM electron transport layer $\dagger$}

\author{
Junta Kagae, \$ Takaaki Yamanaka, \$ Shun Takahashi and Kenichi Yamashita (D) *
}

\begin{abstract}
The fabrication method of a perovskite absorption layer on a $[6,6]$-phenyl- $C_{61}$-butyric acid methyl ester (PCBM) electron transport layer was investigated for application to perovskite/Si tandem photovoltaic devices. A dry/wet hybrid method that involves thermal evaporation of a $\mathrm{Pbl}_{2}$ precursor followed by spin coating of an organic cation solution was found to be a useful means to form a perovskite layer without destruction of the underlying PCBM layer. To form the perovskite layer densely packed with crystals of large grain size and having smooth surface morphology, the rotational speed of the spin coating and the mixing ratio of organic cations were carefully modified. By using this modified absorption layer, a photovoltaic device fabricated under atmospheric exposure conditions showed a power conversion efficiency of $\sim 10.3 \%$ without any large hysteresis. These results have great importance to develop a production technology for high performance tandem solar cells.
\end{abstract}

\section{Introduction}

Lead halide perovskites have excellent optoelectronic functions and are thus promising materials for various electronic and photonic device applications such as solar cells, ${ }^{\mathbf{1 - 3}}$ lightemitting diodes, ${ }^{4,5}$ and optically pumped lasers. ${ }^{6,7}$ One important application of these materials is their use as an absorption layer of a top cell in a tandem photovoltaic device with a crystal silicon (c-Si) bottom cell. ${ }^{8-13}$ Recent studies of the c-Si/perovskite tandem devices demonstrate that the power conversion efficiency (PCE) of $\sim 31 \%$ is theoretically possible, which is beyond the Shockley-Queisser limit defined in a single junction cell. ${ }^{8}$ Therefore the device architecture and fabrication methods of the c-Si/perovskite tandem solar cells should be investigated further to achieve better performance and to facilitate mass production.

Recent studies have shown that one of the key factors for high performance tandem devices is the constitution of intermediate layers between the absorption layers of top and bottom cells, which engage in extraction, transport, and recombination of photoexcited carriers. ${ }^{\mathbf{1 0 , 1 1}}$ Fullerene derivatives such as [6,6]phenyl- $\mathrm{C}_{61}$-butyric acid methyl ester (PCBM) are useful candidates for an n-type carrier extraction layer that extracts electrons from the perovskite top cell and transports them to the recombination layer (e.g. a transparent intermediate electrode

Faculty of Electrical Engineering and Electronics, Kyoto Institute of Technology, Matsugasaki, Sakyo-ku, Kyoto 606-8585, Japan. E-mail: yamasita@kit.ac.jp

$\dagger$ Electronic supplementary information (ESI) available. See DOI: 10.1039/c8ra08022d

\$ J. K. and T. Y. contributed equally. or the interface between highly doped p-type layer of the bottom cell and the n-type fullerene layer itself). ${ }^{\mathbf{1 1} 1 \mathbf{1 4}-\mathbf{1 7}}$ This is because the PCBM can be deposited by a solution-based method at low temperature $\left(<\sim 100{ }^{\circ} \mathrm{C}\right)$ without thermal damage of the $\mathrm{Si}$ bottom cells, which is in contrast with transparent conducting oxides requiring high temperature in their sintering procedure. In addition, a PCBM layer can extract efficiently photoexcited electrons from the perovskite absorption layer. Also its passivation effect on the perovskite layer causes a good electrical property without any significant hysteresis behavior. ${ }^{15-18}$ Therefore a fabrication scheme of the perovskite layer on the PCBM electron transport layer is important to realize tandem photovoltaic cells showing high PCE and stability.

To fabricate the perovskite layer on the PCBM layer successfully, a dry/wet hybrid method, that is thermal evaporation of lead iodide $\left(\mathrm{PbI}_{2}\right)$ on PCBM (dry process) and following spin coating of methylammonium iodide (MAI) solution (wet process), has been used in recent studies. ${ }^{\mathbf{1 1 , 1 5 , 1 9 , 2 0}}$ This hybrid method can avoid destructing the PCBM layer owing to the absence of direct exposure to perovskite precursor solutions. Therefore the PCBM layer can be introduced in the regular device configuration (i.e. an electron transport layer is at the bottom and a hole transport layer is at the top), which results in a high-quality perovskite layer as well as better electron extraction. ${ }^{15}$ Despite this large importance, however, there are few reports on systematic investigations of the film formation mechanism as well as on improvements in the fabrication recipe. In addition, fabrication under atmospheric exposure condition should also be investigated because this method would usually require sample transfers between the dry and wet processes. 
In this study we studied on an improved dry/wet hybrid method for preparing a perovskite absorption layer on a planar PCBM electron transport layer. After deposition of $\mathrm{PbI}_{2}$ by thermal evaporation, we investigated the following wet process under atmospheric condition by comparing the spin coating method and dip coating one and by changing the rotational speed. Furthermore the impacts of formamidinium (FA) and MA cations mixing on the film formation were discussed in detail. Consequently a closely packed polycrystalline film, which was composed of grains in a $\sim 1 \mu \mathrm{m}$ scale and showed a flat and pinhole-free surface morphology, was successfully fabricated. A planar-type photovoltaic device with this absorption layer showed an open circuit voltage as high as $\sim 1.0 \mathrm{~V}$ and a power conversion efficiency (PCE) of $10.3 \%$ without any large hysteresis.

\section{Experimental}

PCBM and poly(3-hexylthiophene-2,5-diyl) (P3HT) were purchased from Sigma-Aldrich. $\mathrm{PbI}_{2}$ and formamidinium iodide (FAI) were purchased from Tokyo Chemical, and MAI was purchased from Wako Pure Chemical. All chemicals were used as purchased from the suppliers. For preparation of the PCBM solution, PCBM powder was dissolved in chlorobenzene $(\mathrm{CBz})$ with a concentration of $20 \mathrm{mg} \mathrm{ml}^{-1}$. The solution was stirred at room temperature for $\sim 1$ hour. For preparation of the $\mathrm{PbI}_{2}$ precursor solution used in the wet process, $\mathrm{N}, \mathrm{N}$-dimethylformamide (DMF, $600 \mathrm{mg}$ ) was mixed with $\mathrm{PbI}_{2}$ powder (462.1 $\mathrm{mg}$ ) and dimethylsulfoxide (DMSO, $70 \mathrm{mg}$ ), and the mixture was stirred at $70{ }^{\circ} \mathrm{C}$ for 1 hour for dissolution. The MAI precursor solution used for the spin coating was prepared by dissolving the MAI precursor (85 $\mathrm{mg}$ ) into 2-propanol $(1.0 \mathrm{ml})$. For MA/FA-mixed perovskite fabrications, the molar fraction of MAI/FAI was adjusted while keeping the total concentration constant. The prepared MAI (or MAI/FAI) precursor solution was stirred at $70{ }^{\circ} \mathrm{C}$ for 1 hour. For the MAI precursor solution used for the dip coating, the MAI precursor $(200 \mathrm{mg}$ ) was dissolved in 2-propanol $(20 \mathrm{ml})$ and the solution was stirred at $70{ }^{\circ} \mathrm{C}$ for 1 hour. For preparation of the P3HT solution, P3HT flakes were dissolved in $\mathrm{CBz}$ with a concentration of $40 \mathrm{mg}$ $\mathrm{ml}^{-1}$. The solution was stirred at room temperature for $\sim 3$ hours.

Photovoltaic devices studied here have a layered structure of $\mathrm{SiO}_{2} /$ fluorinated tin oxide (FTO)/compact (c-) $\mathrm{TiO}_{2} / \mathrm{PCBM} / \mathrm{FA}_{x}-$ $\mathrm{MA}_{1-x} \mathrm{PbI}_{3} / \mathrm{P} 3 \mathrm{HT} / \mathrm{Au}$. The $\mathrm{c}-\mathrm{TiO}_{2}$ layer was deposited onto the FTO by the supplier (Solaronix). The $\mathrm{SiO}_{2} / \mathrm{FTO} / \mathrm{c}-\mathrm{TiO}_{2}$ substrate was cleaned with acetone and ethanol in an ultrasonic bath. The substrate was dried at $80{ }^{\circ} \mathrm{C}$ for 5 minutes and exposed to UV light for 20 minutes under ozone atmosphere to increase the hydrophilicity. Next PCBM was spin coated at $2000 \mathrm{rpm}$ for 30 seconds and then annealed at $100{ }^{\circ} \mathrm{C}$ for 10 minutes on a hot plate. The resultant thickness of PCBM layer was $100 \mathrm{~nm}$. To fabricate the perovskite absorption layer, the $\mathrm{PbI}_{2}$ precursor layer was deposited by thermal deposition or spin coating. In the thermal deposition, the vacuum level was $2 \times 10^{-5}$ Torr, and the deposition rate and time were in ranges of $2-3 \AA^{-1}$ and 15-20 minutes, respectively. The deposition rate was monitored with a crystal oscillator. The resultant thickness of deposited $\mathrm{PbI}_{2}$ was $\sim 300 \mathrm{~nm}$. In the spin coating, the film of $\mathrm{PbI}_{2}$ precursor was fabricated at $3000 \mathrm{rpm}$ for 30 seconds. The $\mathrm{PbI}_{2}$ film was annealed at $70{ }^{\circ} \mathrm{C}$ for 5 minutes. Thereafter a perovskite film was formed by either spin coating or dip coating. In the spin coating, the MAI precursor or the MAI/FAI precursor was spun on the $\mathrm{PbI}_{2}$ layer at 4000 or 1300 rpm for 30 seconds. The $\mathrm{MAPbI}_{3}$ film was annealed at $100{ }^{\circ} \mathrm{C}$ for 5 minutes whereas the $\mathrm{FA}_{x} \mathrm{MA}_{1-x} \mathrm{PbI}_{3}$ film were sequentially annealed; the annealing at $150{ }^{\circ} \mathrm{C}$ for $10 \mathrm{~min}$ followed by that at $100{ }^{\circ} \mathrm{C}$ for $40 \mathrm{~min}$. In the dip coating, the sample, on which the $\mathrm{PbI}_{2}$ layer was deposited, was immersed into the MAI precursor solution for 1 minute and then annealed at $70{ }^{\circ} \mathrm{C}$ for 30 minutes. The thickness of perovskite absorption layer after the synthesis was $\sim 700 \mathrm{~nm}$. Onto the perovskite layer, the P3HT hole transport layer with a thickness of $150 \mathrm{~nm}$ was fabricated by the spin coating at $3000 \mathrm{rpm}$ for 30 seconds. The substrate was dried at room temperature for 30 minutes. Finally a gold top electrode with a thickness of $60 \mathrm{~nm}$ was deposited by vacuum evaporation.

A scanning electron microscope (SEM, S-5200, Hitachi) was employed for the observation of surface morphologies. X-ray diffraction measurements were also performed (Rigaku, RINT2500). The $\mathrm{Cu}-\mathrm{K} \alpha$ line was used. The current density-voltage $(J-V)$ characteristics were measured using a source meter (Model 2400, Keythley) and a solar simulator (XES-40SI, SAN-EI). The $J-V$ curves under both the forward and reverse voltage scanning directions were recorded.

\section{Results and discussion}

First we show the availability of $\mathrm{PbI}_{2}$ thermal evaporation as a deposition method of the perovskite absorption layer onto the PCBM electron transport layer. For this investigation, surface morphology observations by SEM were performed for thermallyevaporated or spin-coated $\mathrm{PbI}_{2}$ layers (Fig. 1a and b) and perovskite layers obtained after reaction with MAI precursor solution (Fig. 1c and d). As shown in Fig. 1a, the PCBM surface was found to be covered with crystalline $\mathrm{PbI}_{2}$ nanoplates deposited by thermal evaporation, while the $\mathrm{PbI}_{2}$ film formed by the spin coating (see Fig. 1b) is more amorphous. For these $\mathrm{PbI}_{2}$ films, MAI precursor solution was spin-coated to form $\mathrm{MAPbI}_{3}$ absorption layers at $4000 \mathrm{rpm}$. As shown in Fig. 1c, the surface morphology of $\mathrm{MAPbI}_{3}$ formed by the $\mathrm{PbI}_{2}$-evaporation is closely packed by tile-shaped crystals with the dimensions of 150-300 nm. On the other hand, the morphology of $\mathrm{MAPbI}_{3}$ formed by the $\mathrm{PbI}_{2}$-spin coating shows clustered crystals with the dimensions of 100-200 nm (see Fig. 1d). It is apparent that the surface flatness in Fig. 1c is much better than that in Fig. 1d. These results clearly show that formation of a $\mathrm{MAPbI}_{3}$ layer is largely affected by a pre-deposited $\mathrm{PbI}_{2}$ precursor. Also the porous structure observed in the thermally evaporated $\mathrm{PbI}_{2}$ film possibly promotes the reaction with MAI precursors. This would also affect the degree of crystallinity in the $\mathrm{MAPbI}_{3}$ crystals. These results demonstrate that the $\mathrm{PbI}_{2}$ thermal evaporation is one of the available means for preparing the $\mathrm{MAPbI}_{3}$ absorption layer on the PCBM electron transport layer. More importantly, 

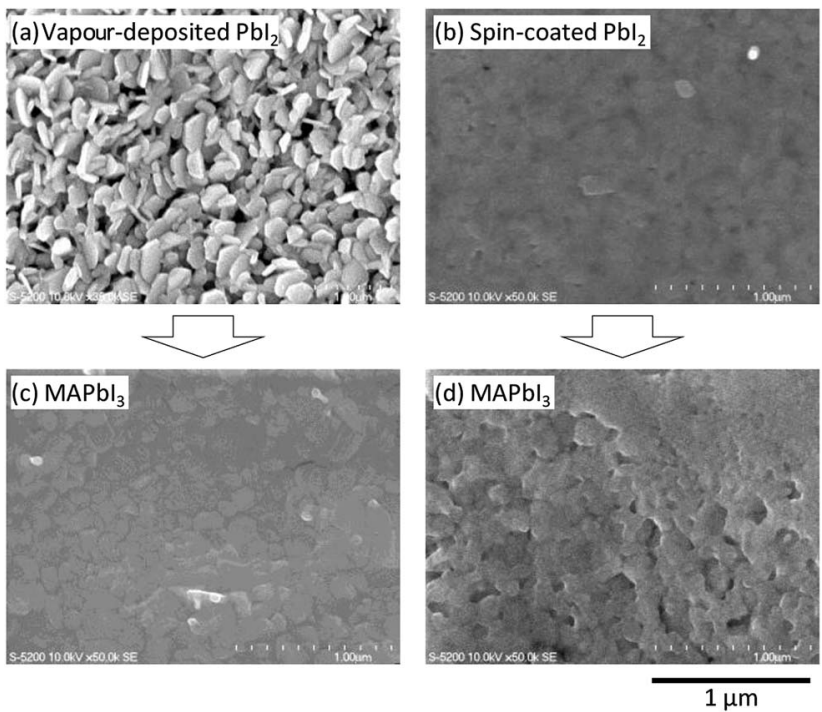

Fig. 1 SEM images of $\mathrm{Pbl}_{2}$ precursor films prepared by (a) vapour deposition method and (b) spin coating method. (c) and (d) SEM images of $\mathrm{MAPbl}_{3}$ perovskite films prepared by MAI spin coating from the $\mathrm{Pbl}_{2}$ films of (a) and (b), respectively.

we confirmed that the $\mathrm{PbI}_{2}$-spin coating degrades the photovoltaic performance significantly due to the destruction of the underlying PCBM layer (see Fig. S1 in the ESI†). This is not the case in the deposition scheme, as shown in the following.

We also investigated a dip coating method as the means to prepare the $\mathrm{MAPbI}_{3}$ perovskite layer from the evaporated $\mathrm{PbI}_{2}$ (see Fig. S2a in the ESI $\dagger$ ). It is apparent that, as compared to the layer prepared by the spin coating (Fig. 1c), the grain size is smaller (130-200 nm) and the growth mode is more threedimensional'. This crystal growth mode would be due to the too rapid reaction of $\mathrm{PbI}_{2}$ with MAI. As shown in Fig. S2b in the $\mathrm{ESI}, \uparrow \mathrm{X}$-ray diffraction (XRD) intensity of the $\mathrm{MAPbI}_{3}$ prepared by the dip coating was as small as one half of that prepared by the spin coating. This result implies that the rapid reaction by the dip coating disturbs homogenous growth of the perovskite crystals. To make matter worse, the immersion time in the dip coating method was limited up to 1 minute because the peeling off of the film from the PCBM underlayer (soluble to the solvent) must be avoided. Namely, we can find that the MAI precursor volume and reaction rate are uncontrollable in the dip coating method.

When we introduced the method of MAI spin coating, on the other hand, the rotational speed was found to be an effective parameter to control them. As shown in a wide-area SEM image of Fig. 2a, the $\mathrm{MAPbI}_{3}$ surface after the spin coating at $4000 \mathrm{rpm}$ still includes residual clustered $\mathrm{PbI}_{2}$. This would be due to the lack of MAI precursor and/or the too short reaction time. When the spin speed was reduced to $1300 \mathrm{rpm}$ (see Fig. 2b), the volume of residual $\mathrm{PbI}_{2}$ was further decreased because of the further promotion in reaction and thus the grain size was also enlarged from $\sim 100 \mathrm{~nm}$ to $\sim 300 \mathrm{~nm}$. By using this recipe, we were able to form $\mathrm{a} \mathrm{MAPbI}_{3}$ film without significant degradation at the PCBM interface, which was confirmed in the photovoltaic performance as described later.
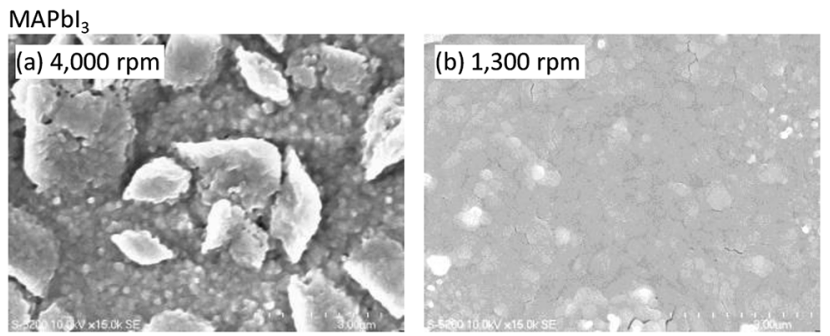

$\mathrm{FA}_{0.25} \mathrm{MA}_{0.75} \mathrm{Pbl}_{3}$
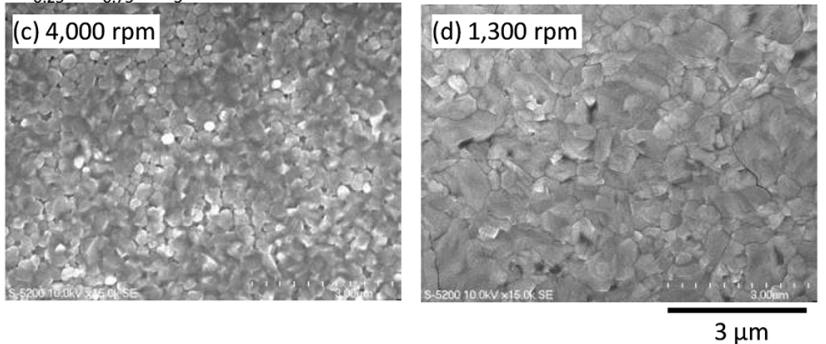

Fig. 2 Wide-area SEM images of $\mathrm{MAPbl}_{3}$ films prepared by spin coating of MAI precursor solution at (a) 4000 and (b) $1300 \mathrm{rpm}$. (c) and (d) SEM images of $\mathrm{FA}_{0.25} \mathrm{MA}_{0.75} \mathrm{Pbl}_{3}$ films prepared by $\mathrm{FAl} / \mathrm{MAl}$ spin coating at 4000 and $1300 \mathrm{rpm}$, respectively.

Next let us see cases of $\mathrm{FAPbI}_{3} / \mathrm{MAPbI}_{3}$-mixed perovskite films. We fabricated $\mathrm{FA}_{x} \mathrm{MA}_{1-x} \mathrm{PbI}_{3}$ films with $x=0,0.2,0.25$, and 0.5 by the spin coating of FAI/MAI mixed precursor solution on the evaporated $\mathrm{PbI}_{2}$. As shown in Fig. $\mathrm{S} 3$ in the ESI, $\uparrow$ the films only with $x=0\left(\mathrm{MAPbI}_{3}\right)$ or $0.25\left(\mathrm{FA}_{0.25} \mathrm{MA}_{0.75} \mathrm{PbI}_{3}\right)$ were successfully fabricated. The yellow and orange films at $x=0.2$ or 0.5 are due to the bleaching of perovskite and the appearance of $\delta$-phase perovskite, respectively. ${ }^{21}$ These results show an importance of molar fraction ratio to enhance perovskite stability, ${ }^{22-25}$ especially under the ambient condition. Fig. $2 \mathrm{c}$ and d show wide-area SEM images of the $\mathrm{FA}_{0.25} \mathrm{MA}_{0.75} \mathrm{PbI}_{3}$ films. It is apparent that the average grain size of crystals increases by introducing FAI, as reported in a previous paper. ${ }^{25}$ When the

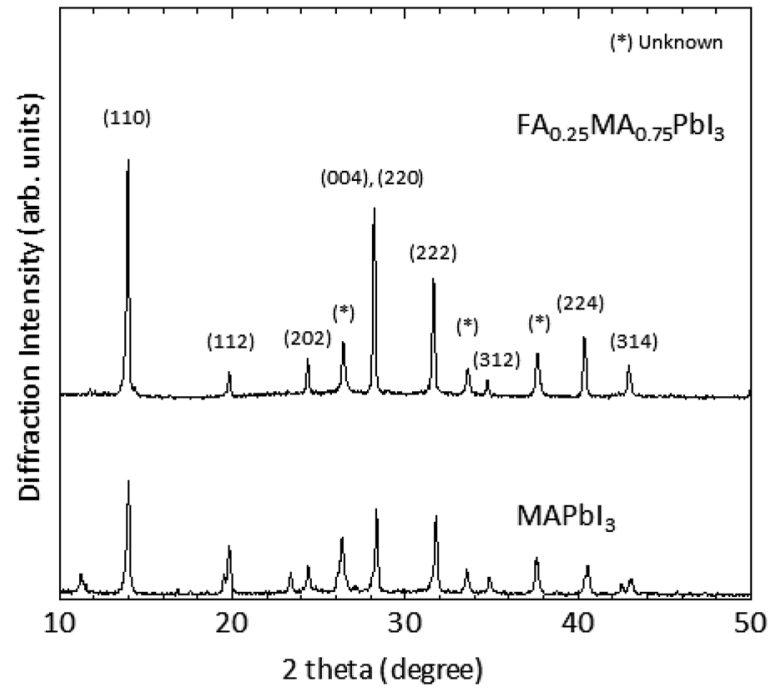

Fig. 3 XRD patterns of $\mathrm{FA}_{0.25} \mathrm{MA}_{0.75} \mathrm{Pbl}_{3}$ and $\mathrm{MAPb}_{3}$ films prepared by spin coating of precursor solutions at $1300 \mathrm{rpm}$. 

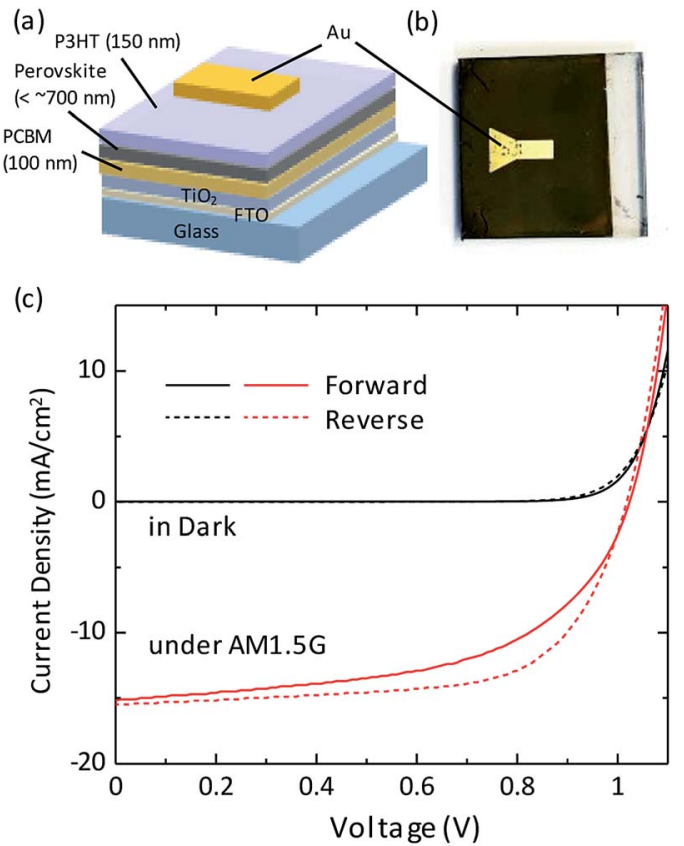

Fig. 4 (a) A schematic of photovoltaic device structure. Detailed fabrication procedures and thickness of each layer are shown in Experimental section. (b) Overview image of photovoltaic sample. (c) Typical current density-voltage $(J-V)$ curves for a photovoltaic device with $\mathrm{FA}_{0.25} \mathrm{MA}_{0.75} \mathrm{Pbl}_{3}$ absorption layer prepared by $\mathrm{FAl} / \mathrm{MAl}$ spin coating at $1300 \mathrm{rpm}$ onto thermally evaporated $\mathrm{Pbl}_{2}$. Black and red curves show the $J-V$ characteristics in dark and under AM1.5G, respectively. Solid and dashed curves exhibit the data at forward and reverse scans in the voltage.

schemes of low-speed spin coating and FA/MA mixing were combined (see Fig. 2d), the grain size of crystal was enlarged further to $\sim 1 \mu \mathrm{m}$. The large grains lead to the closely-packed and almost pinhole-free perovskite film formation. The film quality obtained here is comparable with a case of dual-source thermal deposition method. ${ }^{26}$ A possible mechanism for the high-quality film formation by the FA/MA mixing is the formation of stable cubic perovskite. ${ }^{25}$ We also performed XRD measurement as shown in Fig. 3. The (110) diffraction peak intensity of the $\mathrm{FA}_{0.25} \mathrm{MA}_{0.75} \mathrm{PbI}_{3}$ was $\sim 1.2$ times larger than that of $\mathrm{MAPbI}_{3}$, demonstrating that the crystallinity is also further improved by the FA/MA mixing.

Finally we show photovoltaic characteristics of a solar cell device where the perovskite absorption layer was fabricated by the hybrid method described above. Fig. 4a and b shows the device structure and the appearance. PCBM and P3HT were used as the electron and hole transport layers (ETL and HTL), respectively. Fig. 4c shows current density-voltage $(J-V)$ properties under dark condition and AM 1.5G illumination for the best performance device fabricated by the $\mathrm{PbI}_{2}$-thermal evaporation and the FAI/MAI-spin coating at $1300 \mathrm{rpm}$ (corresponding to the sample of Fig. 2d). The $J-V$ curve at the reverse scan shows a filling factor (FF) of 0.67 without pronounced hysteresis characteristics. The short-circuit current density $J_{\mathrm{sc}}$ and the open-circuit voltage $V_{\mathrm{oc}}$ are $15.2 \mathrm{~mA} \mathrm{~cm}^{-2}$ and $1.02 \mathrm{~V}$, respectively. As a result, the PCE of $10.3 \%$ is achieved. For comparison, we also measured $J-V$ properties for the devices fabricated by the MAI-spin coating at $1300 \mathrm{rpm}$ (corresponding to Fig. $2 \mathrm{~b}$ ) and that fabricated by the FAI/MAI-spin coating at $4000 \mathrm{rpm}$ (corresponding to Fig. 2c). These results are shown in Fig. S4 in the ESI $\dagger$ and summarized in Table 1 . The enhancement in $J_{\mathrm{sc}}$ by the FA/MA mixing (from 6.48 to $15.2 \mathrm{~mA} \mathrm{~cm}^{-2}$ ) is mainly due to the improvement of the perovskite crystallinity. Also, as compared Fig. $2 \mathrm{c}$ with $2 \mathrm{~d}$, the enhancement in $J_{\mathrm{sc}}$ by controlling the spin speed (from 2.29 to $15.2 \mathrm{~mA} \mathrm{~cm}^{-2}$ ) is caused by the enlargement of the average crystal grain size. $V_{\text {oc }}$ did not show significant variation among the samples, demonstrating the well stabilized recombination losses at the ETL/perovskite and perovskite/HTL interfaces. A stability test was performed for a device fabricated by FAI/MAI-spin coating at $1300 \mathrm{rpm}$ as shown in Fig. S5 in the ESI. $\dagger$ The initial performance as large as $\sim 6 \%$ in PCE was improved to $>10 \%$ after one day. A possible reason of this improvement is the slow evaporation of high boiling point solvents (CBz, DMF, and DMSO). After two days later, the device exhibited degradation in $\mathrm{FF}$ and increase in the hysteresis characteristic. While these negative features should be improved, the performance obtained in the reversed scan shows high stability even after 1 week ( $\sim 8 \%$ in PCE).

It should be noted that all the device fabrications in this study, except for the thermal evaporation, were intentionally processed under the atmospheric exposure conditions $(\mathrm{Rh} \sim$ 40-60\%). Furthermore the devices were not encapsulated. Even so, the PCE larger than $10 \%$ was found to be possible. This result would not be so bad because PCEs of devices with the similar compositional ratio (20-30\% of FA) are reported to be in a range of $17-19 \%$ when the device were fabricated in a grove box filled with nitrogen and encapsulated in measurements. ${ }^{25}$ Furthermore this method would be improved further by optimizing the mixing schemes, e.g. hybridization with the caesium

Table 1 Photovoltaic parameters of solar cell devices with $\mathrm{FA}_{x} \mathrm{MA}_{1-x} \mathrm{Pbl}_{3}$ absorption layer

\begin{tabular}{|c|c|c|c|c|c|}
\hline & & $J_{\mathrm{sc}}\left(\mathrm{mA} \mathrm{cm}{ }^{-2}\right)$ & $V_{\mathrm{oc}}(\mathrm{V})$ & $\mathrm{FF}$ & PCE (\%) \\
\hline \multirow[t]{2}{*}{$\mathrm{MAPbI}_{3}(1300 \mathrm{rpm})$} & Forward & $-7.28 \pm 0.86$ & $1.03 \pm 0.01$ & $0.51 \pm 0.11$ & $3.78 \pm 0.29$ \\
\hline & Reverse & $-8.47 \pm 2.02$ & $1.04 \pm 0.02$ & $0.61 \pm 0.06$ & $5.46 \pm 0.75$ \\
\hline & Reverse & $-2.15 \pm 0.13$ & $1.02 \pm 0.01$ & $0.57 \pm 0.01$ & $1.26 \pm 0.10$ \\
\hline \multirow{2}{*}{$\mathrm{FA}_{0.25} \mathrm{MA}_{0.75} \mathrm{PbI}_{3}(1300 \mathrm{rpm})$} & Forward & $-14.94 \pm 2.49$ & $0.99 \pm 0.03$ & $0.51 \pm 0.05$ & $7.63 \pm 1.29$ \\
\hline & Reverse & $-16.18 \pm 3.09$ & $0.97 \pm 0.05$ & $0.62 \pm 0.04$ & $9.59 \pm 1.32$ \\
\hline
\end{tabular}


iodide and lead bromide as similar to a very recent study.$^{27}$ Such the optimization will provide the enhanced device performance of the perovskite top cell together with the production feasibility under atmospheric exposure conditions, which is important to achieve high-performance tandem solar cell modules and to develop their mass production technologies.

\section{Conclusions}

We investigated a hybrid dry/wet fabrication procedure for preparing a perovskite absorption layer onto a planar PCBM electron transport layer for applications to tandem photovoltaic devices. It was confirmed that thermal evaporation of $\mathrm{PbI}_{2}$ is available to form a densely packed perovskite layer without destruction of the underlying PCBM layer. To prepare a $\mathrm{MAPbI}_{3}$ layer from the $\mathrm{PbI}_{2}$ precursor film, the spin coating of MAI precursor solution at a slow rotational speed ( $1300 \mathrm{rpm})$ resulted in a smooth surface morphology without residual $\mathrm{PbI}_{2}$ clusters owing to the well-controlled MAI precursor volume and reaction rate. When FAI was mixed into the perovskite absorption layer, furthermore, average grain size of the perovskite crystal was enlarged to $\sim 1 \mu \mathrm{m}$ and the density of the grain boundary was significantly decreased. A photovoltaic device composed of this improved absorption layer showed a power conversion efficiency of $\sim 10.3 \%$ without any large hysteresis. It should be noted that the fabricated device has undergone the atmospheric exposure processes. Therefore these findings will provide important information to develop the production technologies of perovskite/Si tandem solar cell.

\section{Conflicts of interest}

There are no conflicts to declare.

\section{Acknowledgements}

K. Y. thanks to JSPS KAKENHI Grant No. $15 \mathrm{H} 03974$ and $18 \mathrm{H} 01476$.

\section{Notes and references}

1 A. Kojima, K. Teshima, Y. Shirai and T. Miyasaka, J. Am. Chem. Soc., 2012, 131, 6050-6051.

2 M. M. Lee, J. Teuscher, T. Miyasaka, T. N. Murakami and H. J. Snaith, Science, 2012, 338, 643-647.

3 H.-S. Kim, C.-R. Lee, J.-H. Im, K.-B. Lee, T. Moehl, A. Marchioro, S.-J. Moon, R. Humphry-Baker, J.-H. Yum, J. E. Moser, M. Grätzel and N.-G. Park, Sci. Rep., 2012, 2, 591. 4 Z.-K. Tan, R. S. Moghaddam, M. L. Lai, P. Docampo, R. Higler, F. Deschler, M. Price, A. Sadhanala, L. M. Pazos, D. Credgington, F. Hanusch, T. Bein, H. J. Snaith and R. H. Friend, Nat. Nanotechnol., 2014, 9, 687-692.

5 H. Cho, S. u-H. Jeong, M.-H. Park, Y.-H. Kim, C. Wolf, C.-L. Lee, J. H. Heo, A. Sadhanala, N. S. Myoung, S. Yoo, S. H. Im, R. H. Friend and T.-W. Lee, Science, 2015, 350, 1222-1225.
6 F. Deschler, M. Price, S. Pathak, L. E. Klintberg, D.-D. Jarausch, R. Higler, S. Hüttner, T. Leijtens, S. D. Stranks, H. J. Snaith, M. Atatüre, R. T. Phillips and R. H. Friend, J. Phys. Chem. Lett., 2014, 5, 1421-1426.

7 G. Xing, N. Mathews, S. S. Lim, N. Yantara, X. Liu, D. Sabba, M. Grätzel, S. Mhaisalkar and T. C. Sum, Nat. Mater., 2014, 13, 476-480.

8 G. E. Eperon, M. T. Hörantner and H. J. Snaith, Metal halide perovskite tandem and multiple-junction photovoltaics, Nat. Rev. Chem., 2017, 1, 0095.

9 P. Löper, S.-J. Moon, S. M. de Nicolas, B. Niesen, M. Ledinsky, S. Nicolay, J. Bailat, J.-H. Yum, S. De Wolfa and C. Ballifa, Phys. Chem. Chem. Phys., 2015, 17, 1619-1629.

10 J. P. Mailoa, C. D. Bailie, E. C. Johlin, E. T. Hoke, A. J. Akey, W. H. Nguyen, M. D. McGehee and T. Buonassisi, Appl. Phys. Lett., 2015, 106, 121105.

11 J. Werner, C.-H. Weng, A. Walter, L. Fesquet, J. P. Seif, S. De Wolf, B. Niesen and C. Ballif, J. Phys. Chem. Lett., 2016, 7, 161-166.

12 K. A. Bush, A. F. Palmstrom, Z. J. Yu, M. Boccard, R. Cheacharoen, J. P. Mailoa, D. P. McMeekin, R. L. Z. Hoye, C. D. Bailie, T. Leijtens, I. Marius Peters, M. C. Minichetti, N. Rolston, R. Prasanna, S. Sofia, D. Harwood, W. Ma, F. Moghadam, H. J. Snaith, T. Buonassisi, Z. C. Holman, S. F. Bent and M. D. McGehee, Nat. Energy, 2017, 2, 17009.

13 F. Sahli, J. Werner, B. A. Kamino, M. Bräuninger, R. Monnard, B. Paviet-Salomon, L. Barraud, L. Ding, J. J. Diaz Leon, D. Sacchetto, G. Cattaneo, M. Despeisse, M. Boccard, S. Nicolay, Q. Jeangros, B. Niesen and C. Ballif, Nat. Mater., 2018, 17, 820-826.

14 C. Tao, S. Neutzner, L. Colella, S. Marras, A. R. S. Kandada, M. Gandini, M. De Bastiani, G. Pace, L. Manna, M. Caironi, C. Bertarelli and A. Petrozza, Energy Environ. Sci., 2015, 8, 2365-2370.

15 F. Fu, T. Feurer, T. Jänger, E. Avancini, B. Bissig, S. Yoon, S. Bucheler and A. N. Tiwari, Nat. Commun., 2015, 6, 8932.

16 J. H. Kim, C.-C. Chueh, S. T. Williams and A. K.-Y. Jen, Nanoscale, 2015, 7, 17343-17349.

17 L. Kegelmann, C. M. Wolff, C. Awino, F. Lang, E. L. Unger, L. Korte, T. Dittrich, D. Neher, B. Rech and S. Albrecht, ACS Appl. Mater. Interfaces, 2017, 9, 17245-17255.

18 A. H. Ip, L. N. Quan, M. M. Adachi, J. J. McDowell, J. Xu, D. H. Kim and E. H. Sargent, Appl. Phys. Lett., 2015, 106, 143902.

19 F. Fu, L. Kranz, S. Yoon, J. Löckinger, T. Jänger, J. Perrenoud, T. Feurer, C. Gretener, S. Buecheler and A. N. Tiwari, Phys. Status Solidi A, 2015, 212, 2708-2717.

20 H. A. Abbas, R. Kottokkaran, B. Ganapathy, M. Samiee, L. Zhang, A. Kitahara, M. Noack and V. L. Dalal, APL Mater., 2015, 3, 016105.

21 J. Dai, Y. Fu, L. H. Manger, M. T. Rea, L. Hwang, R. H. Goldsmith and S. Jin, J. Phys. Chem. Lett., 2016, 7, 5036-5043.

22 N. Pellet, P. Gao, G. Gregori, T.-Y. Yang, M. K. Nazeeruddin, J. Maier and M. Grätzel, Angew. Chem., Int. Ed., 2014, 53, 3151-3157. 
23 N. J. Jeon, J. H. Noh, W. S. Yang, Y. C. Kim, S. Ryu, J. Seo and S. I. Seok, Nature, 2015, 517, 476-480.

24 F. Ji, L. Wang, S. Pang, P. Gao, H. Xu, G. Xie, J. Zhang and G. Cui, J. Mater. Chem. A, 2016, 4, 14437-14443.

25 Y. Zhang, G. Grancini, Y. Feng, A. M. Asiri and M. K. Nazeeruddin, ACS Energy Lett., 2017, 2, 802-806.
26 M. Liu, M. B. Johnston and H. J. Snaith, Nature, 2013, 501, 395-398.

27 T. Singh and T. Miyasaka, Adv. Energy Mater., 2018, 8, 1700677. 